\title{
Yield Response to Stimulation when D/2 Rubber Clones Are Tapped at D/3 Frequency Using Yield Stimulants
}

\author{
R.C.W.M.R.A. Nugawela ${ }^{1 *}$ and K.B. Karunasekera ${ }^{2}$
}

\begin{abstract}
Low frequency tapping (LFT) is adopted in rubber plantations to mitigate issues related to harvesting using conventional systems. The performance with LFT will depend on the efficacy of stimulation, harvesting and latex collection. A yield response curve for stimulation under ideal conditions would be useful to the rubber growers to determine the efficacy of their stimulation programs. The study was conducted using a rubber field tapped on panel BO 1 and using two commercially available yield stimulants. The highest yield response for both stimulants was at the first tapping after stimulation but it was relatively high with ethrel than mortex. However, with both stimulants the yield response continued during the entire study period with a declining trend.
\end{abstract}

Keywords: Low frequency tapping, Rubber, Yield stimulation

\footnotetext{
${ }^{1}$ Department of Plantation Management, Faculty of Agriculture and Plantation Management, Wayamba University of Sri Lanka, Gonawila 60170, Sri

Lanka

${ }^{2}$ Sapumalkande Group, Lalan Rubbers (Pvt) Ltd., Dehiowita

*asokanugawela@yahoo.com
}

\section{INTRODUCTION}

Low frequency tapping (LFT), e.g., tapping of clones recommended to be tapped at $d / 2$ frequency on a $d / 3$ frequency, is a need when considering the issues associated with harvesting of rubber plants. Among many, some of the important issues associated with $\mathrm{d} / 2$ tapping are, a) vacant tapping blocks due to lack of harvesters, b) poor quality of tapping as a result of engaging unskilled harvesters, c) high tapping costs due to rather low harvester productivity, d) shorter tapping cycles due to high bark consumption rates and e) poor income levels to both harvesters and land owners (Nugawela, et al., 2000, Rodrigo et al., 2004).

It is proven that $d / 3$ tapping of $d / 2$ clones together with the use of yield stimulants, i.e. low frequency tapping (LFT), could mitigate all issues associated with $d / 2$ tapping which were identified above (Nair et al., 2004). However, to reap all the potential benefits of low frequency tapping with yield stimulation the recommendations on methods for yield stimulation, latex collection and monitoring the yield response to stimulation needs to be strictly adopted.

For effective and meaningful monitoring of the yield response to stimulation the potential outcome from stimulation should be known upfront. Hence, a field trial was conducted to develop a standard yield response curve when trees are stimulated adhering to all recommendations. Further, the efficacy of different types of stimulants available in the market was also tested in this study. 


\section{MATERIALS AND METHODS Experimental Area}

A 7.24 ha field planted in the year 2000 with clone RRIC 102 at Mahaoya Group, Deraniyagala in the Kegalle District was selected for the study. The field is being tapped on panel BO-1 using the tapping system 1/2S d/3. ET 2.5\%. Ba 1.6(2.5). 4/y. In this field two out of the three tapping blocks assigned to a harvester was selected for the study.

\section{Experimental Design}

The task size of the field was ca. 300. Yield stimulation was undertaken on a split task basis, i.e. only one half of the block stimulated at a time. The number of trees actually stimulated in the half identified to be stimulated and the total number of tappable trees in the unstimulated half were counted. Out of the two tapping blocks selected for the study one tapping block was stimulated using Ethrel whilst in the other tapping block Mortex was used as the yield stimulant.

\section{Data Collection}

In each of the two tapping blocks selected for the study, on each tapping day after undertaking the yield stimulation, latex was collected separately from the stimulated trees and from the non-stimulated trees. Subsequently, the latex volume and the metrolac reading were determined to estimate the total dry rubber harvested from stimulated and non-stimulated trees in each of the two tapping blocks selected for the study. The total dry rubber harvested from stimulated and none stimulated trees were divided by the corresponding number of trees tapped to calculate the average yield per tree per tapping $(\mathrm{gtt})$ of both stimulated and non-stimulated trees. Data collection was continued for about eleven consecutive tappings to develop a yield response curve.

\section{Data Analysis}

In each tapping day the difference between the average gtt of stimulated (gtt-st) and non-stimulated trees (gtt-nst) was calculated to determine the percentage increase in gtt of stimulated trees (Y). The following formula was used for the purpose.

$\mathrm{Y}=[(\mathrm{gtt}-\mathrm{st}-\mathrm{gtt}-\mathrm{nst}) / \mathrm{gtt}-\mathrm{nst}] * 100$

The percentage increase in gtt was then plotted against corresponding tap to develop a yield response curve subsequent to stimulation for the two types of yield stimulants tested in this study.

\section{RESULTS AND DISCUSSION}

For both types of yield stimulants tested, the yield response was highest in the first tapping after the yield stimulation. In the first tapping after the yield stimulation, the increase in gtt of stimulated trees was 143 and 86 percent for Ethrel and Mortex respectively (Figure 1). However, the first tapping after stimulation was interrupted by rain for both Ethrel and Mortex stimulated blocks. Therefore, the potential yield response in the first tapping after stimulation could be higher than what is 
recorded in this study. Further, some of the subsequent tappings were also interrupted by rain and details are given in Table 1 .

During the second tapping, the percentage increase in $\mathrm{gtt}$ of trees stimulated with Ethrel showed a marked drop when compared to the previous tapping. However, the gtt drop in the trees stimulated with Mortex was marginal for the same tapping (Figure 1).

From the percentage increase in gtt during subsequent tappings, it is evident that the yield response to stimulation declines more rapidly with Mortex than with Ethrel. The average \% increase in gtt of stimulated trees during the eleven tappings subsequent to stimulation is 63 and $36 \%$ for Ethrel and Mortex respectively. Hence, amongst the two types of yield stimulants tested it could be concluded that Ethrel is more effective than Mortex in yield stimulation.

The actual gtt levels recorded over the study period in both Ethrel and Mortex stimulated trees together with their control trees are given in Figure 2. It is evident that the yield response and sustaining of the yield response is relatively better with Ethrel than with Mortex.

As per the findings of this study the increase in gtt that should be expected from the stimulated trees are given in Figure 1. Therefore, the management could use this yield response curve to monitor the efficiency of their stimulation programs. Accordingly, stimulated tapping blocks showing lower \% increase in gtt need to be identified, possible reasons detected and rectified. This monitoring process of yield response is vital to achieve the potential benefits of low frequency tapping with stimulation.

Table 1. Effect on rain on tapping days recorded during study period in blocks stimulated with Ethrel and Mortex.

\begin{tabular}{|c|c|c|}
\hline $\begin{array}{c}\text { Tapping } \\
\text { No. }\end{array}$ & $\begin{array}{l}\text { Mortex } \\
\text { block }\end{array}$ & Ethrel Block \\
\hline 1 & $\begin{array}{c}\text { Rain } \\
\text { interference }\end{array}$ & $\begin{array}{c}\text { Rain } \\
\text { interference }\end{array}$ \\
\hline 2 & $\begin{array}{l}\text { Normal } \\
\text { tapping }\end{array}$ & $\begin{array}{l}\text { Normal } \\
\text { tapping }\end{array}$ \\
\hline 3 & $\begin{array}{l}\text { Normal } \\
\text { tapping }\end{array}$ & $\begin{array}{l}\text { Normal } \\
\text { tapping }\end{array}$ \\
\hline 4 & $\begin{array}{l}\text { Normal } \\
\text { tapping }\end{array}$ & $\begin{array}{c}\text { Rain } \\
\text { interference }\end{array}$ \\
\hline 5 & $\begin{array}{c}\text { Rain } \\
\text { interference }\end{array}$ & $\begin{array}{l}\text { Normal } \\
\text { tapping }\end{array}$ \\
\hline 6 & $\begin{array}{l}\text { Normal } \\
\text { tapping }\end{array}$ & $\begin{array}{c}\text { Rain } \\
\text { interference }\end{array}$ \\
\hline 7 & $\begin{array}{l}\text { Normal } \\
\text { tapping }\end{array}$ & $\begin{array}{l}\text { Normal } \\
\text { tapping }\end{array}$ \\
\hline 8 & $\begin{array}{c}\text { Rain } \\
\text { interference }\end{array}$ & $\begin{array}{c}\text { Rain } \\
\text { interference }\end{array}$ \\
\hline 9 & $\begin{array}{l}\text { Normal } \\
\text { tapping }\end{array}$ & $\begin{array}{l}\text { Normal } \\
\text { tapping }\end{array}$ \\
\hline 10 & $\begin{array}{l}\text { Normal } \\
\text { tapping }\end{array}$ & $\begin{array}{l}\text { Normal } \\
\text { tapping }\end{array}$ \\
\hline 11 & $\begin{array}{c}\text { Rain } \\
\text { interference }\end{array}$ & $\begin{array}{l}\text { Normal } \\
\text { tapping }\end{array}$ \\
\hline
\end{tabular}

The potential percentage increase in gtt of the stimulated trees following the yield 


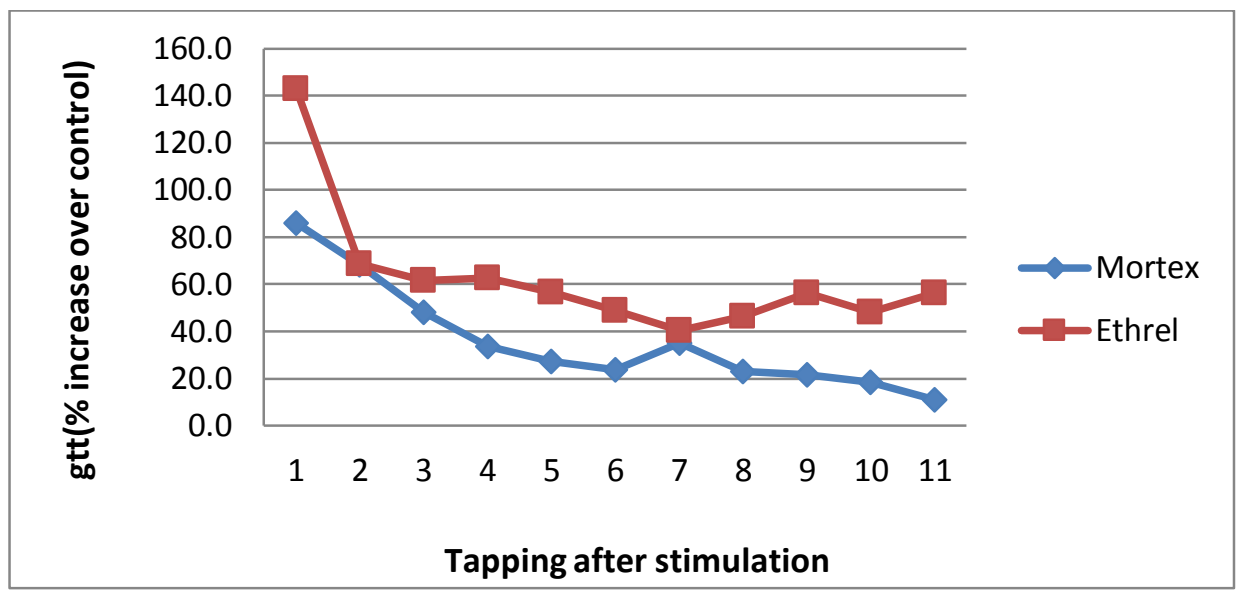

Figure 1. The yield response to stimulants Ethrel and Mortex

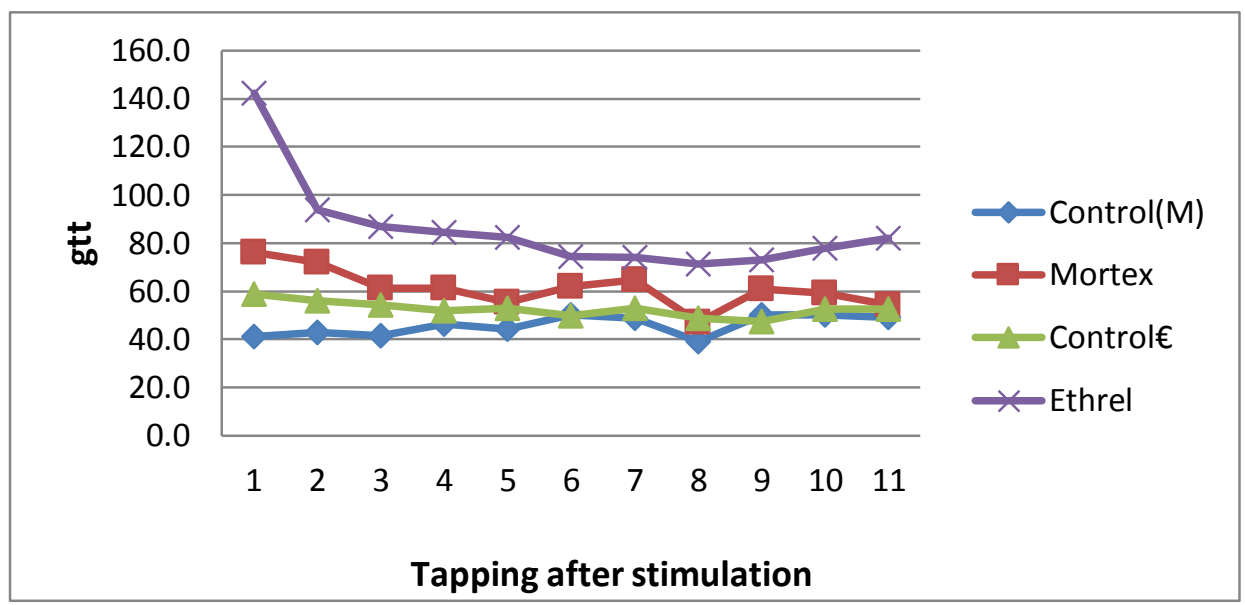

Figure 2. The actual gtt of stimulated and control trees over the study period

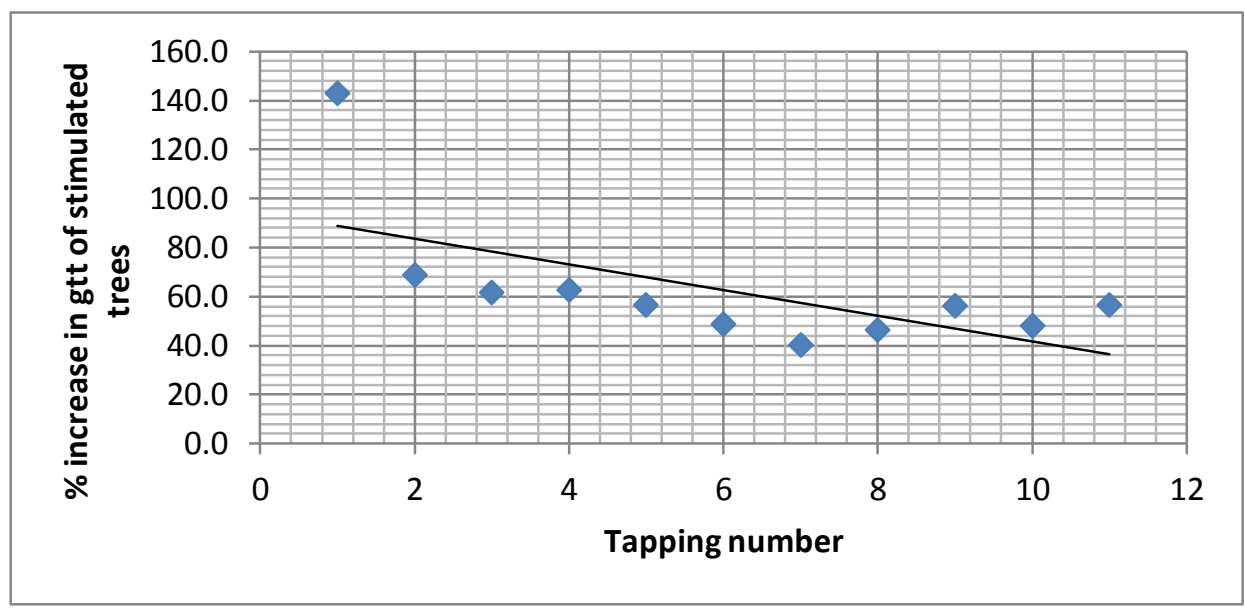

Figure 3. The percentage increase in gtt that should be expected from stimulated trees 
stimulation when tapped at $1 / 2 \mathrm{~S} d / 3$ ET $2.5 \%$. Ba 1.6(2.5) 4/y should be as indicated in Figure 3. This is derived by fitting a regression to the yield response curve resulted from stimulation with ethrel. However, since there was rain interferences on certain tapping days the $\%$ increase in gtt of stimulated trees could be even higher than the values evident from Figure 3 under weather conditions conducive for harvesting. This study was done with clone RRIC 102 and there could be clonal differences as well with regard to the yield response to stimulation. Nevertheless, until yield response curves are established for different clones, Figure 3 could be used as a guideline to monitor the efficacy of stimulation and latex collection programs in the plantations.

\section{REFERENCES}

Nair, U., Nair, R., Thomas, B.M., Gopalakrishnan, J. (2004). Latex Diagnosis in relation to Exploitation Systems in Clone RRII 105. Journal of Rubber Research, 7(2): 127-137.

Nugawela, A. Peries, M.R.C., Wijesekera, S. and Samarasekera, R.K. (2000). Evaluation of $d / 3$ tapping with stimulation to alleviate problems related to $\mathrm{d} / 2$ tapping of Hevea. Journal of the Rubber Research Institute of Sri Lanka, 83: 49-61.

Rodrigo, V.H.L., Wickramarathna, N.A.A.D., Vidanapathirana, R.D. (2004). Productivity and tapper shortage in rubber plantations; Low frequency tapping can address the shortage of tappers in rubber plantations of Sri Lanka. In: Proceedings of the First Symposium on Plantation Crop Research, Colombo, Sri Lanka July 8-9 2004, 32- 42. 